\title{
Effects of physical training on myocardial ischaemia in patients with coronary artery disease
}

\author{
J A RAFFO, * I Y LUKSIC, $C$ C T KAPPAGODA,ł D A S G MARY, \\ W WHITAKER, R J LINDEN
}

From the Department of Cardiovascular Studies, University of Leeds, and Departments of Medical Cardiology, Eastern and Western Districts, Leeds Area Health Authority, Leeds

SUMMARY The effects of a simple physical training programme were investigated in a prospective and randomised trial in patients with stable angina pectoris using a modified exercise test. Twenty-four patients with ischaemic heart disease and an ischaemic response to conventional exercise electrocardiography were randomised into two groups: 12 patients took part in a training programme and 12 patients were allocated to a control group (no training). Exercise testing was performed sequentially at entry to the study and six months afterwards. At both studies we determined the heart rate at the same level of ischaemic ST segment depression (HR/ST threshold), the duration of the test, and relation of heart rate to the exercise load.

The HR/ST threshold increased only in patients who underwent the exercise programme, suggesting indirectly that training resulted in the ability to do more work and attain a higher degree of myocardial oxygen consumption at the same level of myocardial ischaemia. In addition, training led to an increase in the duration of the test and to a reduction in heart rate at any level of submaximal exercise load.

It is concluded that physical training in anginal patients results in an enhancement of myocardial oxygen availability.

Clinical exercise testing has been extensively used to provoke electrocardiographic changes attributed to ischaemia and to assess changes in functional capacity in patients with ischaemic heart disease, ${ }^{12}$ and, by serial exercise testing, to assess the results of physical training programmes. ${ }^{2-4}$ However, most of these studies have been limited to the consideration of improvement in exercise capacity, or the consequences of the reduction in heart rate and blood pressure at a given level of exercise, that is the ability to perform more work before the onset of angina at the same heart rate and blood pressure. $^{256} \mathrm{~A}$ relatively smaller number of studies have investigated levels of heart rate and blood pressure during myocardial ischaemia using subjective criteria, for example anginal pain, ${ }^{5-7}$ thus investigating the ability to perform more work and attain a higher heart rate and blood pressure at the occurrence of anginal pain.

\footnotetext{
^Present address: Sede Oriente Universidad de Chile, Chile. tPresent address: Hospital Paula Jaragesemada, Chile.

$\ddagger$ Present address: Division of Cardiology, Department of Medicine, University of Alberta, Canada.

Received for publication 29 August 1979
}

In this report, the effect of a convenient physical training programme known to improve cardiorespiratory fitness was investigated in patients with stable angina pectoris. ${ }^{8} \mathrm{~A}$ modified exercise test relating levels of heart rate and systemic blood pressure to an objectively determined level of myocardial ischaemia was shown to be sensitive enough to detect improvement in the ability to attain a higher heart rate and blood pressure at the same objective level of myocardial ischaemia.

\section{Subjects and methods}

Twenty-four patients in whom the diagnosis of stable angina pectoris was confirmed by obtaining an ischaemic response during exercise electrocardiography in each, and in addition by selective coronary arteriography in 11 patients, were selected for the investigation. Patients with hypertension, valve disease, cardiac arrhythmia, and patients on digoxin, beta-blocker, or nifedipine therapy were excluded from the study.

On entry to the study, the patients were randomised into two groups. One group consisted of 12 
patients (10 men and two women) who undertook a six-month programme of physical training. The remaining 12 patients (11 men and one woman) did not participate in the training programme but continued their normal daily activities. Clinically, the two groups were managed identically by the consultant cardiologist (WW). Each patient was advised to stop smoking and avoid increases in body weight. All patients were followed-up independently in the cardiology outpatient clinic and whenever deemed necessary on clinical grounds their management was modified according to the routine practice by the consultant cardiologist (WW). Thus, in each patient trinitrate therapy alone was adequate at the entry to the study to control anginal pain. However, during the period of study, beta-blocker or nifedipine therapy was instituted when the patient developed deterioration of anginal symptoms as judged independently by the cardiologist (see results). At the time of entry to the investigation and at the end of six months the patients were studied using an exercise electrocardiography test.

\section{EXERCISE TEST}

The exercise test was performed on an electrically braked bicycle ergometer (Elema Schonander, type 380) with the patients in the upright posture. The patients pedalled at $60 \mathrm{rpm}$ against a continuous series of incremental loads; the initial load being $150 \mathrm{kpm} / \mathrm{min}$. The workload was increased in steps of $150 \mathrm{kpm} / \mathrm{min}$ at three-minute intervals. The end point of the test was defined as the occurrence of ischaemic ST segment depression on an electrocardiogram recorded from CM5 position. The heart rate (beats/min) was obtained from the electrocardiogram during the last minute of every workload, when it attained a constant level. After a 40-minute rest period, the patients performed a second test in which incremental workloads, each of three minutes' duration, were separated by rest periods. The initial load was the same as that which, in the previous test, resulted in the highest heart rate response before the onset of ischaemic ST depression. Subsequent loads were increased in smaller steps of $25 \mathrm{kpm} / \mathrm{min}$ so as to effect a smaller step increase in heart rate; such a technique allowed a more accurate estimation to be made of the lowest heart rate response at which an ischaemic ST depression occurred. The systemic blood pressure was measured in the left arm using an electronic sphygmomanometer (Elag-Koln) at each load when the heart rate had reached a steady value.

The occurrence of ischaemic ST segment depression which indicated the end point of the test was defined as a net ST segment depression of $0.1 \mathrm{mV}$, at $80 \mathrm{~ms}$ after the $\mathrm{J}$ point of the electro- cardiogram, ${ }^{9}$ in the presence or absence of anginal pain. The heart rate (HR) and the product of heart rate and systolic blood pressure (RPP) at this end point were termed the HR/ST threshold and $\mathrm{RPP} / \mathrm{ST}$ threshold, respectively. This end point also determined the point at which the duration of the continuous test in minutes was measured. The heart rate/load relation was expressed in terms of computed regression lines.

\section{TRAINING PROGRAMME}

The patients randomised into the training group undertook the Canadian Air Force programme (5BX/XBX) under supervision in the hospital. This programme was considered suitable since it required only 11 to 12 minutes of daily physical training, and since it has been shown to improve cardiorespiratory fitness in normal subjects, ${ }^{8}$ and in patients after cardiac surgery. ${ }^{10}$ The programme lasted six months, and during hospital sessions the patients exercised with electrodes attached in CM5 position. The patients started training at the lowest physical capacity level, and progressed by increasing this level according to their age and sex. ${ }^{11}$ If the level of exercise was well tolerated the patient was asked to perform the same level at home during the week and return so that the level could be adjusted under supervision. If, during the performance of an increased level of exercise, anginal pain and/or ischaemic ST depression occurred, the patients were maintained at the previous level of exercise.

\section{REPEATABILITY OF TEST}

The tolerance limits of the measurements of HR/ST threshold were studied in five patients. After a preliminary test to familiarise the patient, three successive tests were performed on three consecutive days, and the HR/ST thresholds obtained were used for analysis of repeatability of the test, in a blinded fashion as was previously described ${ }^{9}$; all tracings were copied and the five used in the repeatability tests were randomly interspersed by a person other than the observer.

\section{Results}

Initially, changes in both heart rate and systolic blood pressure (SBP) were analysed in terms of $\mathrm{HR} / \mathrm{ST}$ threshold and RPP/ST threshold. However, the initial values of SBP at the onset of ischaemic ST segment ( $176 \mathrm{mmHg}$ mean; range 155 to $210 \mathrm{mmHg})$ were not different $(2 \mathrm{p}>0.20$; paired $t$ test) from those obtained at the end of the study $(171 \mathrm{mmHg}$ mean; range 150 to $210 \mathrm{mmHg}$ ). Therefore, the heart rate alone was used to analyse the results, rather than RPP. Thus, in the presence 
of an unchanged SBP, the use of heart rate alone would first have the relative virtue of being measured to a recognised accuracy from the electrocardiogram. Secondly, the sensitivity of the test relates basically to the level of heart rate, since at the last incremental load step during the discontinuous test only heart rate changes were observed, SBP remaining constant in the face of small load increments. Finally, analysis of individual changes in rate-pressure product yielded results which were effectively the same as those from heart rate measurement alone (Tables 1 and 2).

Table 1 Exercise testing in 12 patients after physical training

\begin{tabular}{|c|c|c|c|c|c|c|c|}
\hline \multirow[t]{2}{*}{ Subject } & \multicolumn{2}{|c|}{$\begin{array}{l}\text { Duration of } \\
\text { test (min) }\end{array}$} & \multirow{2}{*}{$\begin{array}{l}\text { Submaximal } \\
\text { HR/load } \\
\text { regression } \\
\text { analysis }\end{array}$} & \multicolumn{2}{|c|}{$\begin{array}{l}\text { Heart rate } / S T \\
\text { threshold } \\
\text { (beats/min) }\end{array}$} & \multicolumn{2}{|c|}{$\begin{array}{l}\text { Rate-pressure } \\
\text { product } 110^{-2}\end{array}$} \\
\hline & Initial & Final & & Initial & Final & Initial & Final \\
\hline MP & 6 & 15 & + & 110 & 140 & $24 \cdot 3$ & 33.5 \\
\hline EC & 16 & 18 & - & 130 & 140 & $27 \cdot 7$ & $31 \cdot 7$ \\
\hline $\mathbf{E H}$ & 12 & 15 & - & 95 & 130 & $20 \cdot 2$ & $27 \cdot 7$ \\
\hline RH & 6 & 10 & + & 112 & 120 & $25 \cdot 3$ & $27 \cdot 1$ \\
\hline FL & 12 & 16 & - & 130 & 140 & $26 \cdot 8$ & 33.5 \\
\hline RS & 12 & 17 & + & 128 & 130 & $34 \cdot 0$ & $36 \cdot 3$ \\
\hline MW & 5 & 6 & - & 120 & 122 & 23.9 & $24 \cdot 3$ \\
\hline TS & 12 & 15 & + & 150 & 150 & 30.9 & $29 \cdot 9$ \\
\hline HR & 15 & 15 & - & 130 & 132 & $31 \cdot 1$ & 31.6 \\
\hline VF & 12 & 15 & + & 150 & 150 & $34 \cdot 9$ & 35.9 \\
\hline JM & 15 & 15 & - & 145 & 145 & 40.5 & $34 \cdot 7$ \\
\hline GL & 12 & 12 & - & 115 & 114 & $24 \cdot 5$ & $24 \cdot 3$ \\
\hline
\end{tabular}

$\star+=$ Statistically significant decrease in elevation of $\mathrm{HR} /$ load regression line $(p<0.005$ to $p<0.025)$.

$-=$ No change in slope or elevation of HR/load regression line. tProduct of HR (beats $/ \mathrm{min}) \times \mathrm{SBP}(\mathrm{kPa})$. Conversion factor to $\mathrm{mmHg}, 7 \cdot 52$.

Table 2 Exercise testing in control group of five patients $\star$

\begin{tabular}{|c|c|c|c|c|c|c|c|}
\hline \multirow[t]{2}{*}{ Subject } & \multicolumn{2}{|c|}{$\begin{array}{l}\text { Duration of } \\
\text { test (min) }\end{array}$} & \multirow{2}{*}{$\begin{array}{l}\text { Submaximal } \\
\text { HR/load } \\
\text { regression } \\
\text { analysis }\end{array}$} & \multicolumn{2}{|c|}{$\begin{array}{l}\text { Heart rate/ST } \\
\text { threshold } \\
\text { (beats/min) }\end{array}$} & \multicolumn{2}{|c|}{$\begin{array}{l}\text { Rate-pressure } \\
\text { product } 10^{-8}\end{array}$} \\
\hline & Initial & Final & & Initial & Final & Initial & Final \\
\hline $\begin{array}{l}\text { JT } \\
\text { FC } \\
\text { KF } \\
\text { JW } \\
\text { JK }\end{array}$ & $\begin{array}{r}9 \\
12 \\
9 \\
13 \\
12\end{array}$ & $\begin{array}{r}9 \\
12 \\
6 \\
12 \\
9\end{array}$ & $\begin{array}{l}- \\
\overline{-} \\
-\end{array}$ & $\begin{array}{l}130 \\
130 \\
130 \\
140 \\
120\end{array}$ & $\begin{array}{l}125 \\
125 \\
125 \\
135 \\
120\end{array}$ & $\begin{array}{l}32 \cdot 9 \\
34 \cdot 7 \\
34 \cdot 7 \\
36 \cdot 3 \\
25 \cdot 5\end{array}$ & $\begin{array}{l}29 \cdot 9 \\
26 \cdot 6 \\
28 \cdot 3 \\
30 \cdot 5 \\
25 \cdot 5\end{array}$ \\
\hline
\end{tabular}

*Abbreviations as in Table 1.

tUnits as in Table 1.

\section{REPEATABILITY OF RESULTS}

In the measurement of $\mathrm{HR} / \mathrm{ST}$ threshold, the results showed that using the continuous exercise test procedure the increase in heart rate between the subthreshold load step and the end point of the test was larger in patients before training than after training. Thus step increases in heart rate averaged 22.1 beats/min (range 10 to 40 ) before training and 16.2 beats/min (range 5 to 38 ) after training. In order to avoid the error expected from such large step increases in heart rate, the HR/ST threshold was also studied using the discontinuous test with smaller load increments; the corresponding steps of increases in heart rate averaged 7 beats/min (range 5 to 20).

In five patients the HR/ST threshold was estimated repeatedly, three times over three consecutive days (Table 3 ). In any given patient the difference in HR/ST threshold ranged from 0 to 2 beats $/ \mathrm{min}$. The 95 per cent tolerance limit with 95 per cent confidence of the deviations of measurement from the mean was 2.5 beats/min.

Table 3 Heart rate/ST threshold obtained from three repeated measurements on three consecutive days in five patients

\begin{tabular}{llllll}
\hline Subject & \multicolumn{3}{l}{ Exercise test day } & Mean & $S D$ \\
\cline { 2 - 6 } & 1 & 2 & 3 & & \\
\hline JK & 120 & 118 & 120 & 119.3 & $1 \cdot 2$ \\
GL & 110 & 108 & 110 & 109.3 & $1 \cdot 2$ \\
MW & 122 & 121 & 123 & 122.0 & $1 \cdot 0$ \\
FL & 140 & 138 & 140 & $139 \cdot 3$ & $1 \cdot 2$ \\
JM & 145 & 145 & 145 & 145.0 & 0.0 \\
\hline
\end{tabular}

EFFECT OF TRAINING

All 12 patients in the training group completed the physical training programme uneventfully and in each patient exercise testing was performed before and after physical training (Table 1). All the patients had an ischaemic ST segment response during the post-training test. However, while ischaemic ST segment depression was associated with anginal pain in 11 patients before training, only four had anginal pain at the end point of the exercise test after training. Changes in submaximal heart rate/load relation in every patient were studied using analysis of covariance to detect statistically significant changes in the slope or elevation of the relationship's regression line. ${ }^{12}$ In five patients there was a statistically significant reduction in the elevation of the submaximal heart rate/load regression line ( $p$ from $<0.005$ to $<0.025$ ). In the remaining seven patients the reduction did not reach statistical significance. Nine patients achieved a longer duration of test after training; the increases averaged $2.8 \mathrm{~min}$ (range 1 to 9). In the remaining three patients the duration of the test did not change. Considering the whole group, the increases in test duration were statistically significant $(2 p<0.005$; paired $t$ test $)$.

The HR/ST threshold increased in eight patients by an average of 12.4 beats/min (range 2 to 35), did not change in three patients, and decreased in the remaining patient. The increase in threshold after 
training compared with the threshold before training was statistically significant $(2 p<0.05$; paired $t$ test).

\section{CONTROL GROUP}

In seven of the 12 patients in the control group an independent decision to start medical treatment with drugs was made during routine cardiological follow-up on the basis of deterioration of symptoms. Exercise tests were therefore performed sequentially in five patients on entry to the study and after six months (Table 2). During this period the patients continued their normal daily activities. In all five patients anginal pain accompanied ischaemic ST segment depression during the initial and final tests. The heart rate/load relation did not change either in elevation or slope of the regression line in any of the five patients. The duration of the test decreased by three minutes in two patients, by one minute in one patient, and did not change in the remaining two patients.

The HR/ST threshold decreased in four patients by 5 beats/min and was unchanged in the remaining patient. These changes in all five patients were statistically significant $(2 p<0.02$; paired $t$ test $)$.

\section{SIMILARITY BETWEEN GROUPS}

The results of the initial tests, that is at the start of the investigation, in the training group were similar to those in the control group (Table 4). Thus the differences in duration of the test, in $\mathrm{HR} / \mathrm{ST}$ threshold, and in RPP/ST threshold were not statistically significant $(2 p>0.7 ; 2 p>0.70$; $2 p>0 \cdot 20$, respectively; unpaired $t$ test). The training group comprised 10 men and two women, and their ages averaged 51 years (range 28 to 60 ). The control group (non-training) consisted of 11 men and one woman, and their ages averaged 49 years (range 40 to 57 ). The ages of both groups were similar ( $2 p>0.40$; unpaired $t$ test). A history of previous myocardial infarction was present in three patients of the training group and in one patient of the control group. Coronary arteriography was performed in six patients who undertook the training programme and in five patients of the control group. The number of diseased vessels in these patients was similar in both groups (Table 4).
The similarity in the initial response to exercise testing (exercise duration, HR/ST threshold, and RPP) was maintained (Table 5) when the training group was compared with five patients in the control group who completed the study $(2 p>0.80$; $2 p>0.50 ; 2 p>0.10$, respectively; unpaired $t$ test). The control group comprised four men and one woman and their ages averaged 47 years (range 45 to 50). The difference in age between the resulting control group and the training group was not significant $(2 p>0.10$; unpaired $t$ test). The similarity in findings of coronary arteriography and the incidence of previous myocardial infarction between the two groups of patients was also maintained (Table 5).

\section{Discussion}

Physical training has been used with increasing frequency in the management of patients with angina pectoris; effects of training such as improvement in functional capacity and sense of well-being have been reported. ${ }^{213}$ However, the evidence for direct regression in the level of myocardial ischaemia has not been consistent. While there is experimental evidence from animals indicating improvement in mechanical, vascular, and biochemical characteristics of the myocardium, ${ }^{14-18}$ clinical studies in which left ventricular function, myocardial vascularity, and blood flow were assessed during cardiac catheterisation and angiocardiography have yielded variable results partly because of the uncertainty regarding the sensitivity of the methods used to detect increased blood flow in local ischaemic regions of the myocardium and the difficulty of applying such invasive methods during exercise. ${ }^{619-21}$ Non-invasive techniques such as exercise testing can be used to provoke ischaemic ST segment changes in the electrocardiogram or anginal symptoms and in addition provide a basis for quantitative evaluation of changes in physical capacity and cardiocirculatory response. ${ }^{1272223}$ Exercise electrocardiograph testing has therefore been extensively used to investigate two main potential effects of training; an improvement in work capacity leading to a delayed onset of anginal

Table 4 Data relating to 24 patients at entry to study

\begin{tabular}{|c|c|c|c|c|c|c|c|c|c|}
\hline \multirow[t]{2}{*}{ Group } & \multirow{2}{*}{\multicolumn{2}{|c|}{$\begin{array}{l}\text { Sex } \\
\text { (male-female) }\end{array}$}} & \multirow[t]{2}{*}{$A g e^{\star}(y)$} & \multirow{2}{*}{$\begin{array}{l}\text { Previous } \\
\text { myocardial } \\
\text { infarction }\end{array}$} & \multicolumn{2}{|c|}{ Coronary lesions $¥$} & \multirow{2}{*}{$\begin{array}{l}\text { Duration of } \\
\text { exercise } \\
\text { (minutes) }\end{array}$} & \multirow{2}{*}{$\begin{array}{l}\text { HR/ST threshold* } \\
\text { (beats/min) }\end{array}$} & \multirow{2}{*}{$\begin{array}{l}\text { Rate-pressure } \\
\text { product } \dagger 10^{-2 \star}\end{array}$} \\
\hline & & & & & 1 vessel & 2 vessels & & & \\
\hline Training & 10 & 2 & $28-60(51)$ & 3 & 5 & 1 & $5-16(11 \cdot 3)$ & $95-150(126 \cdot 3)$ & $20 \cdot 2-40 \cdot 5(28 \cdot 7)$ \\
\hline Control & 11 & 1 & $40-57$ (49) & 1 & 4 & 1 & $9-13(10 \cdot 8)$ & $110-150(128 \cdot 2)$ & $22.9-37.9(31.2)$ \\
\hline
\end{tabular}

*Range (mean). †Units as in Table 1. \$Luminal obstruction of $>75$ per cent in any of the anterior descending, circumflex and the right coronary artery. 
symptoms and a direct improvement in myocardial oxygen supply, that is the onset of ischaemic pain at a higher level of myocardial demand. ${ }^{2-7} 13192425$

In the investigations reported above, at least three clinically accessible responses to exercise have been considered. First, circulatory responses were measured in terms of heart rate, systemic blood pressure, and left ventricular ejection time. Secondly, exercise capacity was evaluated as the duration of the test, intensity of workload, and/or total oxygen consumption. Thirdly, the extent of any level of ST segment depression was taken to indicate an ischaemic response. However, the occurrence of anginal pain during the exercise test was used as the end point at which these responses were investigated. ${ }^{2}{ }^{4-7}$ The use of such a subjective reference point suffers from obvious limitations. Distinct variations occur in the duration of the test and heart rate at the onset of angina. ${ }^{26}$ Furthermore, the results of the present study and those of others ${ }^{5}$ show that the relation between the occurrence of angina and ischaemic ST depression can be altered after physical training; after physical training, only four out of 11 patients in this study continued to complain of angina at the onset of ischaemic ST depression. From this evidence a cause and effect relation between training and a delayed onset of subjective appreciation of anginal pain is difficult to confirm or deny. It is obvious, however, that the recognised occurrence of such a subjective factor would lead to false conclusions of an improvement in terms of a higher work capacity or a higher circulatory response.

The evidence for an improvement in work capacity stems from objective studies in which submaximal reference points have been chosen either in terms of load intensity, heart rate, or oxygen consumption..$^{3-51925}$ Using a symptomlimited test, it is to be expected that the heart rate and systemic blood pressure after a training period would be lower at any given level of exercise, thereby enabling a higher intensity and duration of exercise to be achieved before the onset of angina, that is the improvement in patients with a limited myocardial oxygen supply is the result of a lower myocardial oxygen demand at any given level of exercise. ${ }^{2}{ }^{27}$ Such observations do not objectively confirm or deny a direct improvement in myocardial 'oxygen supply', that is the possibility that physical training results in an improvement in myocardial oxygen supply, in that the patients gain the ability to do more work at a higher myocardial oxygen demand before the objective occurrence of myocardial ischaemia.

To our knowledge the present investigation is the first to provide objective evidence indicating improvement in myocardial 'oxygen supply' after a period of physical training in patients with angina pectoris. It is suggested that this improvement was shown as a higher heart rate during exercise testing which occurred at an objectively determined level of myocardial ischaemia in terms of the widely accepted ischaemic depression of the ST segment in the electrocardiogram. ${ }^{9}$ While known determinants of myocardial oxygen consumption include heart rate, ventricular pressure, size, ejection time, and contractile behaviour, ${ }^{28}{ }^{29}$ heart rate alone provides a simple, reliable measurement in the noninvasive clinical setting. It has been shown to be a fairly accurate correlate of myocardial oxygen demand during upright exercise. ${ }^{30} 31$ The heart rate in this context provides an integral of developed left ventricular wall tension, systolic pressure, and dynamic muscle behaviour over a period of one minute. ${ }^{29}$ Thus, during sequential exercise testing an increase in HR/ST threshold indicates an improvement in oxygen supply since it reflects a higher level of myocardial oxygen demand at the same level of myocardial ischaemia. Conversely, a decrease in this threshold indicates decreased oxygen supply.

It is implicit in these considerations that an increase in HR/ST threshold alone can indicate an improvement in the ability to attain a higher myocardial oxygen demand only if the systolic blood pressure, left ventricular wall thickness, size, contractile behaviour, and ejection time were not reduced by physical training. In respect of systolic blood pressure, the present results have shown that training was not associated with significant changes in systolic blood pressure, as has also been reported in patients with angina pectoris. ${ }^{2}$ Heart

Table 5 Data at entry to study, relating to 17 patients in whom a complete sequential investigation was possible

\begin{tabular}{|c|c|c|c|c|c|c|c|c|c|}
\hline \multirow{3}{*}{$\begin{array}{l}\text { Group } \\
\text { Training }\end{array}$} & \multirow{2}{*}{\multicolumn{2}{|c|}{$\begin{array}{l}\text { Sex } \\
\text { (male-female) }\end{array}$}} & \multirow[t]{2}{*}{$A g e^{\star}(y)$} & \multirow{2}{*}{$\begin{array}{l}\text { Previous } \\
\text { myocardial } \\
\text { infarction }\end{array}$} & \multicolumn{2}{|c|}{ Coronary lesions $\ddagger$} & \multirow{2}{*}{$\begin{array}{l}\text { Duration of } \\
\text { exercise } \\
\text { (minutes) }\end{array}$} & \multirow{2}{*}{$\begin{array}{l}\text { HR/ST threshold } \\
\text { (beats/min) }\end{array}$} & \multirow{2}{*}{$\begin{array}{l}\text { Rate-pressure } \\
\text { product }+10^{-2 \star}\end{array}$} \\
\hline & & & & & 1 vessel & 2 vessels & & & \\
\hline & 10 & 2 & $28-60(51)$ & 3 & 5 & 1 & $5-16(11 \cdot 3)$ & $95-150(126 \cdot 3)$ & $20 \cdot 2-40.5(28.7)$ \\
\hline Control & 4 & 1 & $45-50(47)$ & 1 & 3 & 1 & $9-13(11 \cdot 0)$ & $120-140(130 \cdot 0)$ & $25 \cdot 5-36 \cdot 3(32 \cdot 8)$ \\
\hline
\end{tabular}

«Range (mean).

tUnits as in Table 1.

¥As in Table 4 - 
rate alone or heart rate-pressure produce has been shown to correlate better with myocardial oxygen consumption than did the product of systolic blood pressure, heart rate, and ejection time during upright exercise in normal subjects. ${ }^{31}$ Thus, while the relative importance of systolic ejection period in the determination of myocardial oxygen consumption remains unsettled, ${ }^{29}$ this period has been shown to increase during exercise after training in normal subjects $^{32}$ and in anginal patients ${ }^{22}$; the duration of the ejection time is now thought to be of minor importance in estimating myocardial oxygen consumption. Physical training in the dog has been shown to result in an increase in left ventricular wall thickness in the absence of a significant change in the end-diastolic volume at rest. ${ }^{33}$ An increase in left ventricular wall thickness and in enddiastolic dimensions at rest has been reported in normal subjects after training. ${ }^{34}$ Wallace et al. ${ }^{35}$ used radionuclide angiography to show that physical training in 12 anginal patients resulted in an increase in end-diastolic volume at rest and during exercise testing. The effect of training on left ventricular contractility during exercise in anginal patients is not known but is unlikely to be different from the above. Therefore, the present use of an increase in heart rate at the onset of ischaemic ST segment depression as an indicator of increased myocardial oxygen demand is acceptable for sequential studies in a given subject. The present study has shown that the measurement of the HR/ ST threshold is reproducible in a given patient; the maximum variation in heart rates during repeated measurements did not exceed 2 beats/min. Such a finding is an essential requirement before using this theshold in individual patients. This adequate reproducibility was achieved by a simple exercise test using small step increases in heart rate. An alternative method of ensuring objectivity in measurement would be to use the more sophisticated and complicated computer technique. ${ }^{36}$

Accepting that an increase in HR/ST threshold indicates improvement in myocardial blood supply, that is improvement in the ability to do more work at a higher heart rate before the occurrence of ST segment depression, it is considered that the present results show that physical training is associated with a direct improvement in myocardial blood supply. For instance, firstly, the majority of the patients in the trained group achieved an increase in $\mathrm{HR} / \mathrm{ST}$ threshold (eight of 12 patients). When changes in HR/ST threshold exceeding the 95 per cent tolerance limit of measurement were considered alone, there was still an increase in HR/ST threshold in five out of the 12 patients. These results confirm, therefore, that the increase in HR/ST threshold after a period of physical training can be shown with patients acting as their own control. Secondly, considering the control group separately, seven of the original 12 patients at entry to the study were judged independently to have deteriorated on clinical grounds. The majority of the remaining patients who were not eliminated by clinical assessment of deterioration ended with a decrease in the HR/ST threshold (four out of five patients). Therefore, when patients in the control group were considered, with the patients acting as their own control, natural progression in the myocardial ischaemia could be detected both by clinical assessment and by using the decrease in HR/ST threshold. Finally, these results were confirmed when statistical analysis of sequential results in the two groups as a whole was used. Thus, in the two groups which were similar in respect of age, sex, and initial disability as determined by exercise testing, a significant increase in HR/ST threshold was achieved in the training group and a significant decrease in the threshold was achieved in the absence of physical training in the control group. Throughout the study, none of the patients in these two groups had been started on beta-blocker or nifedipine therapy.

While it was not the purpose of this study to investigate the mechanism(s) involved in this improvement (an increase in HR/ST threshold), such an improvement can be caused by an increase in myocardial oxygen availability which may be brought about by the development of new collateral vessels, an increase in the capacity of existing collaterals, or by biochemical changes either in the blood or in the myocardium. These considerations stem from previously reported experimental evidence. Thus there is evidence that training in rats and dogs leads to an increase in coronary vascularity, maximum coronary blood flow, and myocardial oxygen consumption..$^{15} 173738$ Similarly, significant biochemical alterations were shown to occur in the hearts of rats after training. ${ }^{14} 3940$

The results of this study, therefore, indicate that such convenient but short physical exercises, known to result in an improvement in the capacity to exercise, ${ }^{810}$ can effect directly an increase in myocardial oxygen consumption at a given level of myocardial ischaemia in patients with coronary artery disease.

The authors are grateful to the British Heart Foundation and the Wellcome Trust for financial support. 


\section{References}

${ }^{1}$ Fortuin NJ, Weiss JL. Exercise stress testing. Circulation 1972; 56: 699-712.

${ }^{2}$ Clausen JP. Circulatory adjustments to dynamic exercise and effect of physical training in normal subjects and in patients with coronary artery disease. Prog Cardiovasc Dis 1976; 18: 459-95.

${ }^{3}$ Hellerstein H, Hornsten TR, Goldbarg A, et al. The influence of active conditioning upon subjects with coronary artery disease. Can Med Assoc $\mathcal{F} 1967$; 96: 758-60.

${ }^{4}$ Ben Ari E, Kellermann JJ, Lapitod C, Drory Y, Fisman E, Hayat M. Effect of prolonged intensive training on cardiorespiratory response in patients with angina pectoris. $B r$ Heart $\mathcal{f} 1978$; 40: 1143-8.

${ }^{5}$ Detry J-M, Bruce RA. Effects of physical training on exertional ST-segment depression in coronary heart disease. Circulation 1971; 44: 390-6.

${ }^{6}$ Sim DN, Neill WA. Investigation of the physiological basis for increased exercise threshold for angina pectoris after physical conditioning. $\mathcal{F}$ Clin Invest 1974; 54: 763-70.

'Redwood DR, Rosing DR, Epstein SE. Circulatory and symptomatic effects of physical training in patients with coronary-artery disease and angina pectoris. $N$ Engl f Med 1972; 286: 959-65.

${ }^{8}$ Kappagoda CT, Linden RJ, Newell JP. Effect of the Canadian Air Force training programme on a submaximal exercise test. $Q \mathcal{F}$ Physiol 1979; 64: 185-204. ${ }^{9}$ Raffo JA, Luksic IY, Kappagoda CT, et al. Diagnostic value of routine exercise testing in hospital patients with angina pectoris. $\mathrm{Br} \mathrm{Med} \mathcal{F} 1979$; 2: 295-7.

${ }^{10}$ Newell JP, Kappagoda CT, Linden RJ, Stoker JB, Deverall PB, Watson DA. Physical training after heart valve replacement. Clin Sci Mol Med 1979; 57: 15 P. ${ }^{11}$ Royal Canadian Air Force. Physical fitness. Harmondsworth: Penguin, 1964.

${ }^{12}$ Snedecor GW, Cochran WG. Statistical methods. Ames, Iowa: Iowa State University Press, 1967: 432. ${ }^{13}$ Barry AJ, Daly JW, Preutt EDR, Steinmetz JR, Birkhead NC, Rodahl K. Effects of physical exercise training in patients who have had myocardial infarction. Am $\mathcal{F}$ Cardiol 1966; 17: 1-8.

${ }^{14}$ Scheuer J. Physical training and intrinsic cardiac adaptations. Circulation 1973; 47: 677-80.

${ }^{15}$ Leon AS, Bloor CM. The effect of complete and partial deconditioning on exercise-induced cardiovascular changes in the rat. Adv Cardiol 1976; 18: 81-92.

${ }^{16}$ Carey RA, Tipton CM, Lund DR. Influence of training on myocardial responses of rats subjected to conditions of ischaemia and hypoxia. Cardiovasc Res 1976; 10: 359-67.

${ }^{17}$ Stevenson JAF, Feleki V, Rechnitzer P, Beaton JR. Effect of exercise on coronary tree size in the rat. Circ Res 1964; 15: 265-9.

${ }^{18}$ Bersohn MM, Scheuer J. Effects of physical training on end-diastolic volume and myocardial performance of isolated rat hearts. Circ Res 1977; 40: 510-6.

${ }^{10}$ Kennedy CG, Spickerman RE, Lindsay MI, Markin HT, Frye RL, McCallister BD. One-year graduated exercise program for men with angina pectoris. Mayo
Clin Proc 1976; 51 : 231-6.

${ }^{20}$ Monroe RG. Myocardial oxygen consumption during ventricular contraction and relaxation. Circ Res 1964; 14: 294-300.

${ }^{21}$ Chatterjee K, Matloff JM, Swan HJC, et al. Abnormal regional metabolism and mechanical function in patients with ischemic heart disease. Circulation 1975; 52: 390-9.

${ }^{22}$ Epstein SE, Redwood DR, Goldstein RE, et al. Angina pectoris: pathophysiology; evaluation and treatment. Ann Intern Med 1971; 75: 261-96.

${ }^{23}$ Clausen JP. Effect of physical training on cardiovascular adjustments to exercise in man. Physiol Rev 1977; 57: 779-815.

${ }^{24}$ Bruce RA, Blackman JR, Jones JW, Strait G. Exercise testing in adult normal subjects and cardiac patients. Pediatrics 1963; 32: 742-56.

${ }^{25}$ Kavanagh T, Shephard RJ, Pandit VB, Davey $H$. Exercise and hypnotherapy in the rehabilitation of the coronary patient. Arch Phys Med Rehabil 1970; 51: 578-87.

${ }^{26}$ Smokler PE, MacAlpin RN, Alvaro A, Kattus AA. Reproducibility of a multi-stage near maximal treadmill test for exercise tolerance in angina pectoris. Circulation 1973; 48: 346-51.

${ }^{27}$ Frick MH, Katila M. Hemodynamic consequences of physical training after myocardial infarction. Circulation 1968; 37: 192-202.

${ }^{28}$ Sarnoff SJ, Braunwald E, Welch GH Jr, Case RB, Stainsky WN, Macruz R. Hemodynamic determinants of oxygen consumption of the heart with special reference to the tension-time index. Am $\mathcal{F}$ Physiol 1958; 192: 148-56.

${ }^{29}$ Sonnenblick EH, Ross J Jr, Braunwald E. Oxygen consumption in the heart: newer concepts of its multifactorial determination. Am f Cardiol 1968; 22: 328-36.

${ }^{30}$ Kitamura K, Jorgensen CR, Gobel FL, Taylor HL, Wang Y. Hemodynamic correlates of myocardial oxygen consumption during upright exercise. $\mathcal{F} \mathrm{Appl}$ Physiol 1972; 32: 516-22.

${ }^{31}$ Nelson RR, Gobel FL, Jorgensen CR, Wang $\mathrm{K}$, Wang Y, Taylor HL. Hemodynamic predictors of myocardial oxygen consumption during static and dynamic exercise. Circulation 1974; 50: 1179-89.

${ }^{32}$ Wiley J. Effects of 10 weeks of endurance training on left ventricular intervals. I Sports Med Phys Fitness 1971 ; 11: 104-11.

${ }^{33}$ Wyatt HL, Mitchell JM. Influence of physical training on the heart of dogs. Cir Res 1974; 35: 883-9.

${ }^{34}$ DeMaria A, Neumann A, Lee G, Fowler W, Mason DT. Alterations in ventricular mass and performance induced by exercise testing in man indicated by echocardiography. Circulation 1978; 57: 237-44.

${ }^{35}$ Wallace HG, Berych SK, Jones RH, Goodrich JK. Effects of exercise training on ventricular function in coronary disease (abstract). Circulation 1978; 57 and 58: Suppl II: 197.

${ }^{36} \mathrm{McH}$ enry PL, Phillips JF, Knoebel SB. Correlation of computer-quantitated treadmill exercise electrocardiogram with arteriographic location of coronary artery disease. Am f Cardiol 1972; 30: 747-52. 
${ }^{37}$ Eckstein RW. Effect of exercise and coronary artery narrowing on coronary collateral circulation. Circ Res 1957; 5: 230-5.

${ }^{38}$ Penpargkul S, Scheuer J. The effects of physical training upon the mechanical and metabolic performance of the rat heart. $\mathcal{F}$ Clin Invest 1970; 49: 1859-68.

${ }^{39}$ Penpargkul S, Depke DI, Katz AM, Scheuer J. Effect of physical training on calcium transport by rat cardiac sarcoplasmic reticulum. Circ Res 1977; 40: $134-8$.

${ }^{40}$ Bahn AK, Scheuer J. The effects of physical training on cardiac myosin ATPase activity. Am $\mathcal{f}$ Physiol 1975; 228: 1178-82.

Requests for reprints to Professor R J Linden, Department of Cardiovascular Studies, The University of Leeds, Leeds LS2 9JT. 